\title{
Seizure-like activity leads to the release of BAD from 14-3-3 protein and cell death in hippocampal neurons in vitro
}

\author{
R Meller ${ }^{*, 1}$, CK Schindler ${ }^{1}$, XP Chu ${ }^{1}$, ZG Xiong ${ }^{1}$, JA Cameron ${ }^{1}$, \\ RP Simon ${ }^{1}$ and DC Henshall ${ }^{1}$ \\ ${ }^{1}$ Robert S. Dow Neurobiology Laboratories, Legacy Research, Portland, OR \\ 97232, USA \\ * Corresponding author: R Meller, Robert S. Dow Neurobiology Laboratories, \\ Legacy Clinical Research \& Technology Center, 1225 NE 2nd Avenue, \\ Portland, OR 97232, USA. Tel: 1503413 2581; Fax: 1503413 5465; E-mail: \\ rmeller@downeurobiology.org
}

Received 21.8.02; revised 4.11.02; accepted 28.11.02 Edited by $\mathrm{D}$ Nicholson

\section{Abstract}

Seizure-induced neuronal death may involve engagement of the BCL-2 family of apoptosis-regulating proteins. In the present study we examined the activation of proapoptotic BAD in cultured hippocampal neurons following seizures induced by removal of chronic glutamatergic transmission blockade. Kynurenic acid withdrawal elicited an increase in seizure-like electrical activity, which was inhibited by blockers of AMPA (CNQX) and NMDA (MK801 and AP5) receptor function. However, only NMDA receptor antagonists inhibited calcium entry as assessed by fura-2, and cell death of hippocampal neurons. Seizures increased proteolysis of caspase-3 and terminal deoxynucleotidyl transferase dUTP nick end labelling (TUNEL) of cells. Seizure-like activity induced dephosphorylation of BAD and the disruption of its constitutive interaction with 14-3-3 proteins. In turn, BAD dimerized with antiapoptotic BCL-XI after seizures. However, the absence of neuroprotective effects of pathway intervention suggests that BAD may perform a reinforcement rather than instigator role in cell death following seizures in vitro. Cell Death and Differentiation (2003) 10, 539-547. doi:10.1038/ sj.cdd. 4401206

Keywords: apoptosis; caspase; epilepsy; neuron; BCL-2

\footnotetext{
Abbreviations: AMPA, $\alpha$-amino-3-hydroxy-5-methylisoxazole4-propionic acid; AP5, aminophosphonovaleric acid; CNQX, 6cyano-7-nitroquinoxaline-2,3-dione; ERK, extracellular signalregulating kinase; LDH, lactate dehydrogenase; MAP kinase, mitogen-activated protein kinase; MEK, MAP kinase kinase; NMDA, $N$-methyl-D-aspartate; PI3 kinase, phosphatidylinositol 3 kinase; RSK, ribosomal S6 kinase; TUNEL, terminal deoxynucleotidyl transferase-mediated dUTP nick end labelling; kyn, kyneuric acid.
}

\section{Introduction}

Clinical neuroimaging studies reveal progressive hippocampal atrophy in patients with long-standing epileptic seizures. ${ }^{1-}$ 3 Experimental and now human studies suggest that programmed cell death and/or apoptosis may contribute to the mechanism of neuronal death following seizures based on apoptotic morphology (blebbing, condensation of the nucleus), DNA fragmentation, upregulation of BCL-2 family proteins and activation of the caspase (cysteinyl aspartatespecific protease) family of cell death enzymes in affected cell populations. $^{4-10}$

Mitochondria are critical sites for the initiation and reinforcement of cell death pathways, being a source of apoptogenic factor (e.g. cytochrome c) sequestration and release. ${ }^{11,12}$ Cell death signals that converge on mitochondria are integrated and effected in part by proapoptotic members of the BCL-2 family such as BAX and BAK, ${ }^{13,14}$ events opposed by antiapoptotic members such as BCL-XI. In addition, BCL-2 homology 3 (BH3) domain-only containing death agonists such as $\mathrm{BID}^{15}$ may also trigger cytochrome $c$ release, or potentiate the effect of BAX/ BAK. ${ }^{13,16,17}$

Another member of the proapoptotic BCL-2 family is BAD. ${ }^{18}$ $B A D$ normally resides in an inactive state complexed with the chaperone proteins of the 14-3-3 family. ${ }^{19,20}$ The interaction of BAD with 14-3-3 is crucially dependent on the phosphorylation of BAD on a specific residue (Ser 136). ${ }^{19,21}$ Following apoptotic stimuli and/or dephosphorylation by calcineurin, ${ }^{22}$ BAD is released from 14-3-3 and then dimerizes with $\mathrm{BCL}-\mathrm{XI} .{ }^{23}$ Since $\mathrm{BCL}-\mathrm{XI}$ constitutively sequesters $\mathrm{BAX}$, this triggers the release of $\mathrm{BAX},{ }^{18}$ which then translocates to mitochondria to exert its cell death initiating effect. While recent evidence supports the role of this BAD pathway in in vivo ${ }^{24,25}$ and in vitro ${ }^{26}$ models of neuronal injury, its role in seizure-induced cell death has not been investigated.

We therefore examined whether this pathway is activated in the setting of seizure-induced neuronal injury using an in vitro model in which hippocampal neurons are chronically grown in kynurenic acid (Kyn) and high magnesium, which on withdrawal triggers high-frequency paroxysmal seizure-like discharges. ${ }^{27,28}$ Presently, we demonstrate that seizure-like activity in neuronal cultures activates the BAD cell death pathway, but find this event plays a contributing or even redundant role in the mechanism of neuronal death. 


\section{Results}

\section{Withdrawal of Kyn induces seizure-like activity that is mediated by NMDA and AMPA glutamate receptors}

Seizure-like activity in neuronal cultures, following relief of the chronic glutamatergic transmission block by Kyn, was characterized using whole-cell patch-clamp technique. Following the formation of tight seal and whole-cell configuration, neurons were current-clamped with a membrane potential of $-60 \mathrm{mV}$. As shown in Figure 1, the majority of hippocampal neurons remain quiescent in the presence of Kyn. Upon washout of Kyn, almost all neurons $(n=12)$ displayed seizurelike activity as evidenced by high-frequency firing of action potentials over a slow and sustained membrane depolarization (Figure 1a). Application of NMDA receptor blocker MK801 $(10 \mu \mathrm{M})$ or AP5 $(100 \mu \mathrm{M})$ largely decreased sustained depolarization $(n=4-5)$, with little effect on the firing of action potentials (Figure 1b,c). In contrast, application of CNQX $(20 \mu \mathrm{M})$ completely eliminated the firing of action potentials (Figure 1d).

a

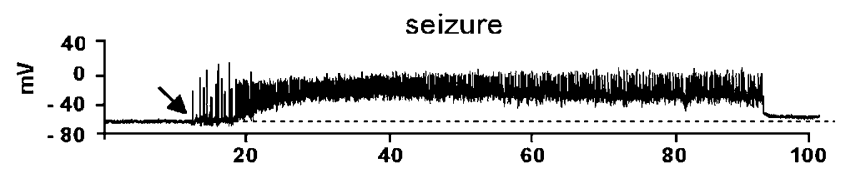

b

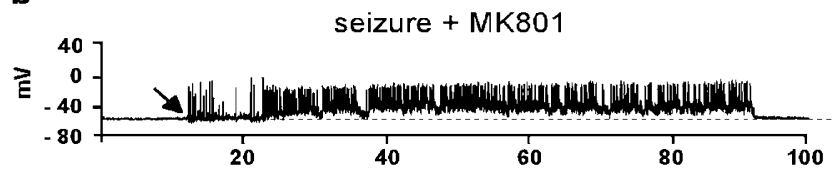

c

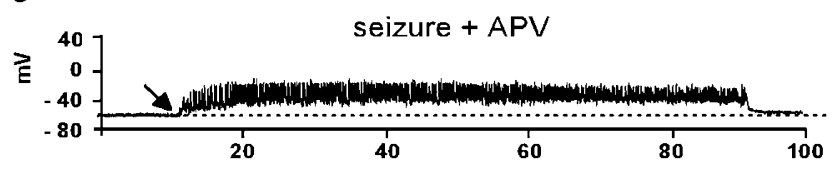

d

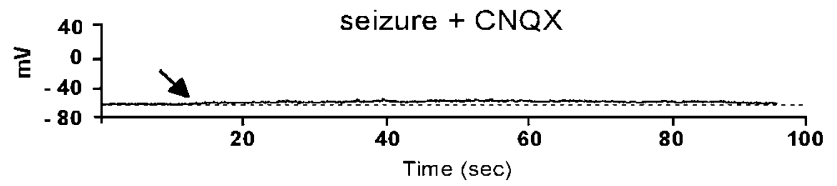

Figure 1 Characterization of seizure-like activity in vitro. Representative wholecell patch-clamp traces showing the induction of seizure-like activity on withdrawal of kyn from the culture media and the effects of MK801, APV or CNQX on such activity. After the formation of whole-cell configuration, neurons were current-clamped with a membrane potential of $-60 \mathrm{mV}$. Upon washout of kyn (as indicated by the arrow), neurons ( $n=12$ ) display seizure-like activity as evidenced by high-frequency firing of action potentials on top of a slow and sustained membrane depolarization (a). Application of NMDA receptor blocker MK801 $(10 \mu \mathrm{M})$ or APV $(100 \mu \mathrm{M})$ during washout of kyn largely decreases sustained depolarization, with little effect on the firing of action potentials (b and $\mathbf{c}$ ). Application of $20 \mu \mathrm{M}$ CNQX completely eliminates the firing of action potentials (d)

\section{Seizure-like activity increases intracellular calcium} via NMDA receptors

Fura-2 calcium imaging revealed that Kyn withdrawal triggers prominent calcium entry (Figure 2a). Calcium entry was subsequently blocked by return of Kyn to cells. MK801 coapplication on withdrawal of Kyn completely blocked calcium entry to neurons (Figure 2b). Furthermore, calcium entry was also blocked by the competitive NMDA antagonist AP5 $100 \mu \mathrm{M}$ ( $n=5$; data not shown). In contrast, CNQX had no significant effect on calcium entry during seizure-like activity in vitro (Figure 2c).

\section{Withdrawal of KA increases cell death in hippocampal cultures}

$\mathrm{LDH}$ assay of cultures determined that seizure-like activity caused a significant increase in LDH release compared to control at all time points investigated (Figure 3a). Cultures subjected to $4 \mathrm{~h}$ Kyn withdrawal and then returned to media containing Kyn showed lower levels of cell death than complete omission of Kyn (Figure 3a). Nevertheless, seizure-like activity provoked submaximal injury as confirmed by greater LDH release following incubation of the cells with the cell death inducing agent staurosporine. $^{29}$

a
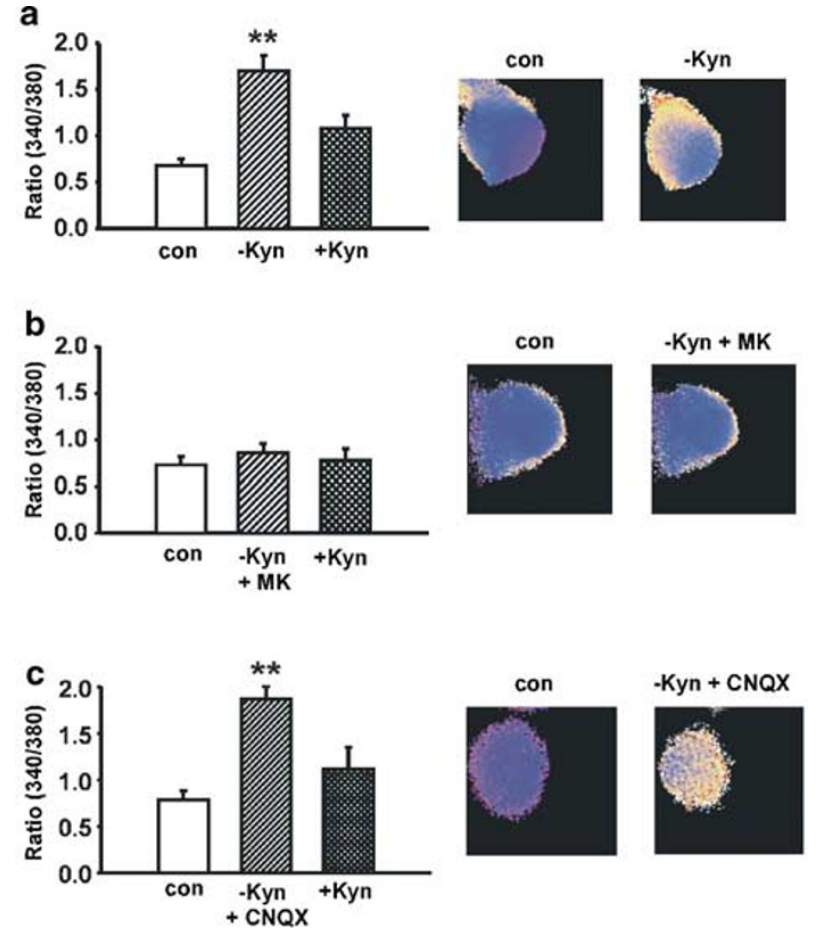

Figure 2 Fura-2 imaging of seizure-induced calcium entry. Fura-2 measurements revealed (a) kyn withdrawal (-Kyn) triggers a significant increase in calcium entry, which is blocked on return of kyn (+Kyn). Panels to the right show representative microscopic imaging of fura-2 in control (blocked) cells and on withdrawal of kyn. (b) Inclusion of MK801 (-Kyn+MK) on induction of seizure-like activity blocked calcium entry to cells. (c) Inclusion of CNQX (-Kyn+CNQX) on induction of seizure-like activity did not block calcium entry on kyn withdrawal. ${ }^{* \star} P$ $<0.01$ for $n=5$ determinations 


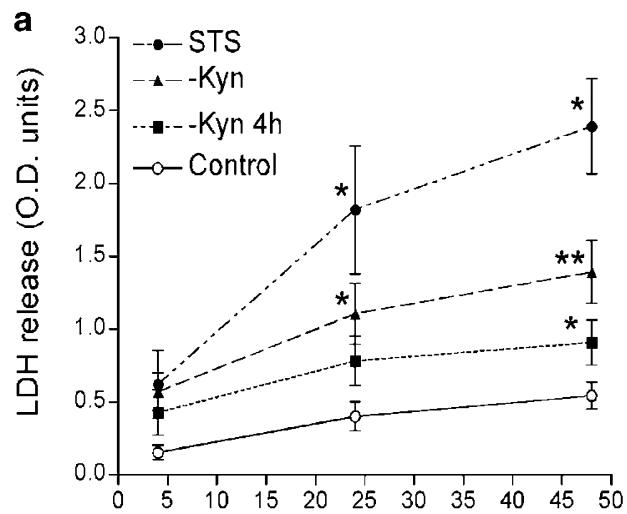

Time (h) after kynurenic acid withdrawal

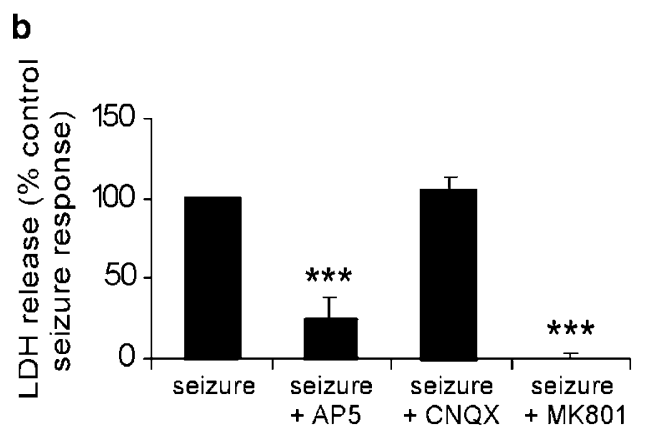

Figure 3 Characterization of cell death following seizures. (a) Graph showing $\mathrm{LDH}$ release following seizures induced by $4 \mathrm{~h}(-\mathrm{Kyn} 4 \mathrm{~h})$ or $48 \mathrm{~h}(-\mathrm{Kyn})$ withdrawal of Kyn. Comparison to treatment of cultures with staurosporine (STS) confirms that Kyn withdrawal does not elicit maximal cell death. (b) Graph showing effects of glutamate receptor antagonist on seizure-induced LDH release in which NMDA but not AMPA receptor antagonists blocked cell death

We next incubated cultures with the noncompetitive antagonist MK801 $(10 \mu \mathrm{M})$, the competitive NMDA receptor antagonist AP5 $(100 \mu \mathrm{M})$ and the AMPA receptor antagonist CNQX $(40 \mu \mathrm{M})$. In contrast to the observations in the electrophysiology experiments but supportive of calcium imaging findings, the increase in LDH release following Kyn withdrawal was abolished in the presence of AP5 and MK801 but not CNQX (Figure 3b).

\section{Seizure-like activity induces cell death with common features of apoptosis}

Following withdrawal of Kyn, there was an increase in TUNEL-positive cells compared with control at 24 and $48 \mathrm{~h}$ (Figure 4a,b). High-power microscopic analysis of TUNEL-positive cells revealed many exhibited features consistent with apoptosis such as condensation and clumping of chromatin and formation of apoptotic bodies (inset in Figure 4a). The time course of the increase in TUNEL-positive cell counts was similar to the increase in LDH release over time, suggesting that many of the cells indeed die by a slow method of cell death, which is consistent with apoptosis.
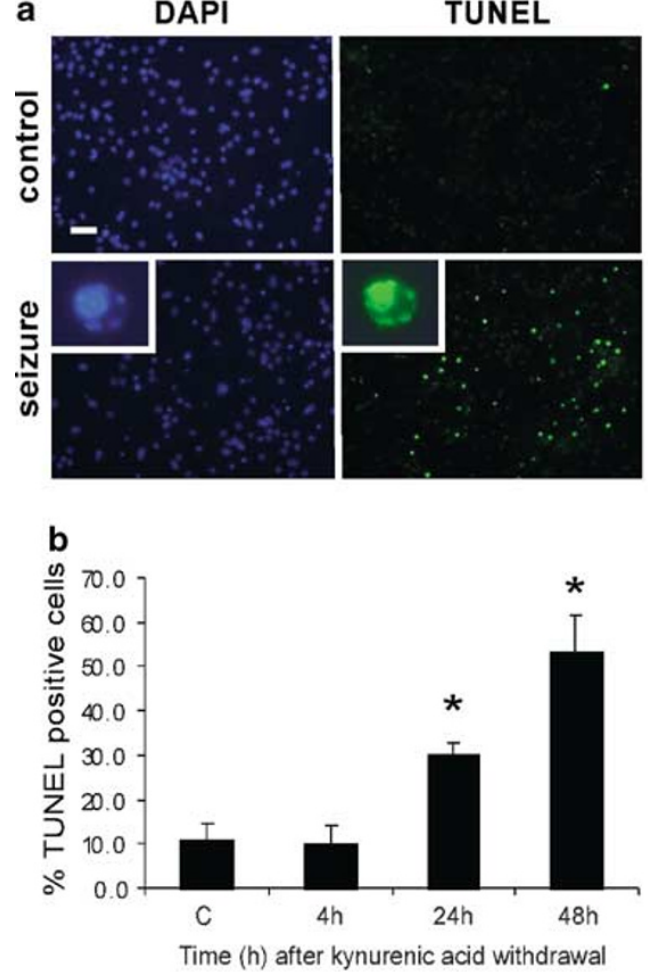

C

d

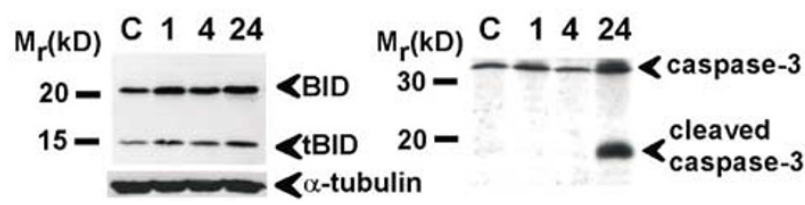

Figure 4 Characterization of cell death following seizures. (a) Photomicrographs showing TUNEL staining of neuronal cultures $24 \mathrm{~h}$ following Kyn withdrawal compared to control. DAPI reveals nuclei. Inset shows a $\times 400$ magnification of a TUNEL-positive cell in which features of apoptosis are seen. Scale bar $=50 \mu \mathrm{m}$. (b) Quantification of time-dependent increase in TUNEL labelling following Kyn withdrawal. ${ }^{*} P<0.05$ versus control. (c) Western blot detection of BID and cleaved (15 kDa) BID after seizures. $\alpha$-Tubulin confirms equivalency of protein loading. (d) Western blot detection of the p19 fragment of cleaved caspase- $324 \mathrm{~h}$ after seizures

To provide biochemical evidence for apoptosis, we examined the expression and proteolysis of BID, a caspase substrate that forms a key link between the extrinsic (death receptor) and intrinsic (mitochondrial) pathways that is cleaved during apoptosis and triggers cytochrome $c$ release. Western blotting confirmed BID expression at the predicted weight of $\sim 22 \mathrm{kDa}$ in hippocampal cultures and expression tended to increase following seizures (Figure 4c). We also detected an increase of the $15 \mathrm{kDa}$ cleaved form of BID from 1 to $24 \mathrm{~h}$ after Kyn withdrawal.

Finally, we examined expression and proteolysis of caspase-3, the key executioner caspase in apoptosis. Using an antibody specific for active caspase-3, we detected a strong increase in caspase- 3 cleavage (p19 fragment) $24 \mathrm{~h}$ following seizure induction (Figure 4d). 
a

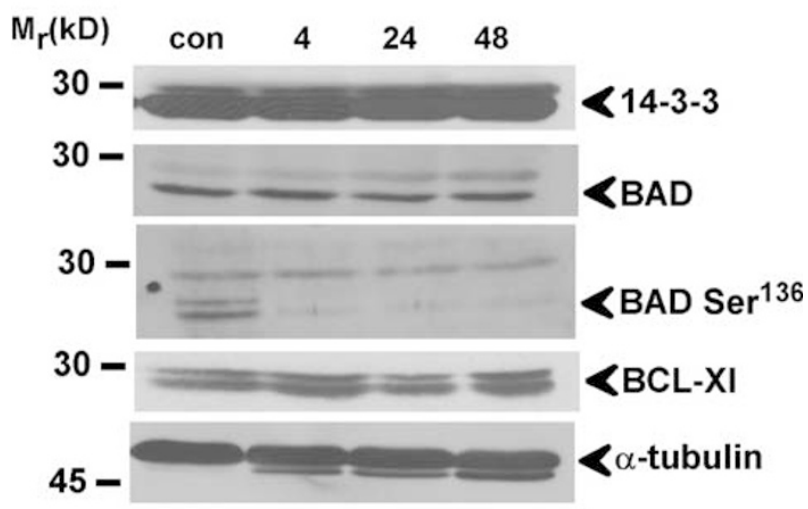

b

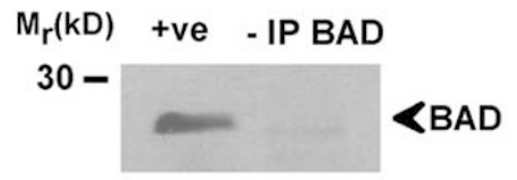

C

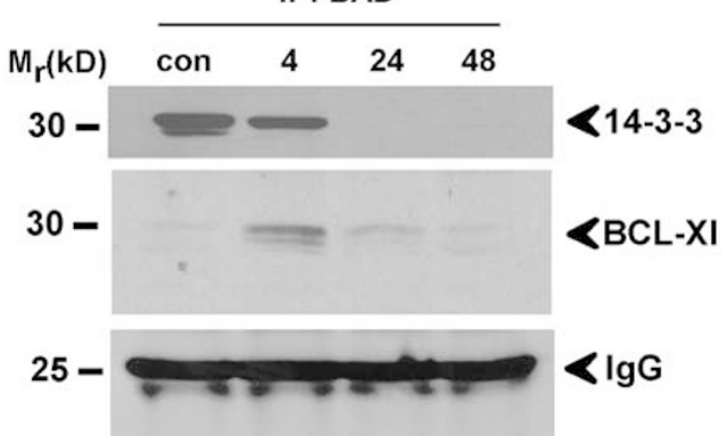

Figure 5 Activation of BAD pathway following seizures in vitro. (a) Western blotting reveals constitutive expression of BAD pathway components. Seizurelike activity had no obvious effects on the expression of 14-3-3, BAD or BCL-XI. PhosphoBAD ${ }^{136}$ levels declined $4-48 \mathrm{~h}$ following seizures. (b) Control immunoprecipitation study experiment showing no BAD is precipitated when the immunoprecipitation antibody (-IP BAD) is omitted. Positive lane (+ve) is whole-cell lysate run concurrently to confirm predicted size. (c) BAD was immunoprecipitated from neuron cultures and then immunoprecipitates were immunoblotted to detect associated proteins. Control cultures exhibited constitutive binding of 14-3-3 but no BCL-XI was present. Following seizures 14-3-3 binding levels declined commensurate with increased BCL-XI binding. Immunoglobulin (IgG) bands show correct antibody loading. Immunoblots are representative of at least two independent experiments

\section{Expression of BAD pathway components following seizure-like activity in vitro}

Expression of 14-3-3, BAD and BCL-XI was constitutively detected in hippocampal cell lysates. Further, expression and phosphorylation levels of all proteins examined were similar to neuronal cultures not grown chronically in Kyn (data not shown). Following withdrawal of Kyn, there were no significant changes in the expression of any of the components of the BAD pathway (Figure 5a). However, activation of BAD was supported by an early decline in phosphoBAD levels in these cultures (Figure 5a).

\section{Seizures trigger dissociation of BAD from 14-3-3 and association with BCL-XI}

We next examined the constitutive and seizure-affected protein-protein interactions of the BAD pathway components using coimmunoprecipitation. Preliminary studies confirmed that the BAD antibody effectively precipitated BAD (Figure 5b and data not shown). In control neuronal cultures there was robust binding of BAD to 14-3-3 and no binding of BCL-XI to BAD immunoprecipitates. In cultures subject to seizures, binding of 14-3-3 to BAD rapidly decreased and this was commensurate with an increase in BCL-XI appearing in BAD immunoprecipitates (Figure $5 \mathrm{c}$ ). Binding of 14-3-3 to BAD was undetectable by $24 \mathrm{~h}$, while binding of $B C L-X I$ to $B A D$ tended to decline after $4 \mathrm{~h}$.

\section{Regulation of BAD phosphorylation}

BAD protein is bound (or resequestered) to 14-3-3 by phosphorylation on a critical residue $\operatorname{Ser}^{136}, 21$ a target of prosurvival protein kinases such as $\mathrm{ERK}_{1 / 2}$ (p42/44 MAP kinase) and Akt. ${ }^{26,31,32}$ It has previously been shown that glutamate-stimulated calcium influx into cells activates calcineurin, a protein phosphatase, which can dephosphorylate $B A D .{ }^{22}$ We first examined the role of these protein kinases as potential counteractive pathways to suppress BAD in this model. Western blotting confirmed the constitutive Akt expression in hippocampal cultures and Akt levels did not change following seizure induction (Figure 6a). Antibodies against the phosphorylated forms of Akt detected constitutive and unchanging levels of Akt $\mathrm{Thr}^{308}$ and Akt Ser ${ }^{473}$ following seizures (Figure 6a). Similarly, Western blotting confirmed constitutive expression of MAP kinase pathway components $\mathrm{MEK}_{1 / 2}, \mathrm{ERK}_{1 / 2}$ and RSK p90 and phosphorylation levels did not change noticeably after seizure induction (Figure 6b).

We next assessed the roles of the prosurvival kinases in the phosphorylation of BAD using U0126, a MAP kinase kinase (MEK) (MAP kinase pathway) inhibitor and the phosphatidylinositol 3 (PI3) kinase inhibitor LY294002, which prevents Akt activation. Immunoblotting confirmed that the MEK inhibitor U0126 selectively reduced phosphorylation of $\mathrm{ERK}_{1 / 2}$, while LY294002 reduced Akt phosphorylation (Figure 6c). Cell death assays revealed that U0126 and LY294002 promoted a small increase in both basal and Kyn withdrawal-induced LDH release, although this did not reach statistical significance (Figure 6d).

\section{Inhibition of the BAD pathway}

Treatment of neuronal cultures with the calcineurin inhibitor FK506 (4 h) reduced the seizure-induced release of Bad from 14-3-3 and formation of the BAD-BCL-XI dimer (Figure 7a). Immunoblotting confirmed that FK506 reduced the depho- 
a

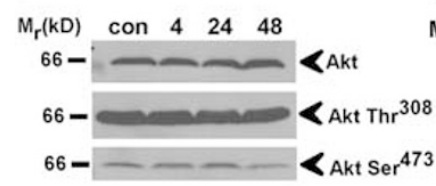

b

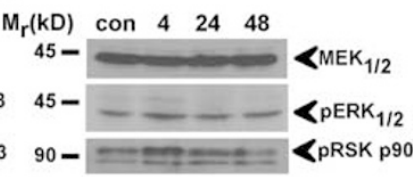

C

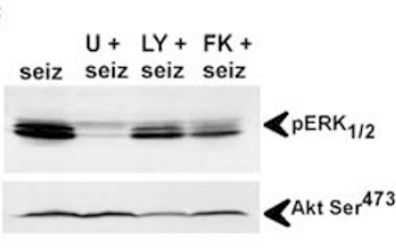

Figure 6 Candidate mediators of BAD phosphorylation. (a) Immunoblotting revealed constitutive expression and phosphorylation of Akt within hippocampal cultures. Seizure induction had no significant effect on Akt activation. (b) Immunoblotting revealed a small early phosphorylation of RSK p90 but no change in MEK or ERK activation. (c) Immunoblots showing basal activation of ERK $_{1 / 2}$ and Akt $4 \mathrm{~h}$ following seizure induction. The MEK inhibitor U0126 (U) markedly reduced activation, while the PI3 kinase/Akt inhibitor LY294002 (LY) and FK506 (FK) had little effect. In contrast, activation of Akt was only reduced by LY294002. (d) Graph comparing seizure-induced LDH release following treatment with MEK inhibitor U0126 (seiz+U) or PI3 kinase inhibitor LY294002 $($ seiz $+L Y)$ did not significantly elevate cell death compared to normal seizure response (seiz)

sphorylation of Bad following seizures (Figure 7b). However, in LDH cell death assays, FK506 was ineffective in reducing cell death following Kyn withdrawal (Figure 7c). Confirming commensurate activation of other cell death pathways despite reduced $B A D$ activation, levels of $\mathrm{B} B \mathrm{D}$ were slightly higher (Figure 7d) in FK506-treated cells, whereas cleaved caspase3 (Figure 7e) levels were unchanged in seizure cultures treated with FK506.

\section{Discussion}

In the present study we provide the first functional evidence for the activation of the BAD pathway following seizure-like activity in an in vitro model. Kyn withdrawal elicited seizurelike electrical activity and neuronal injury as demonstrated by $\mathrm{LDH}$ release and TUNEL staining of cells in a time-dependent manner. While AMPA and NMDA receptor antagonists inhibited seizure activity, only NMDA receptor antagonists inhibited calcium influxes and cell death. Seizure-like activity induced the release of BAD from 14-3-3 and caused a transient increase in BAD-BCL-XI formation, which corresponded with a decrease in phosphorylation of BAD. Finally, pharmacological manipulation suggested that while $B A D$ is activated downstream of calcineurin, its inhibition does not confer effective protection on neurons, perhaps because of commensurate activation of other (BID/caspase-3) cell death pathways. These data suggest that while this pathway is activated by seizures in vitro, BAD performs either a reinforcement role or rather compensatory pathways ensure progression to neuronal death.

a

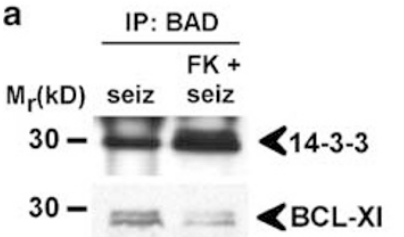

b

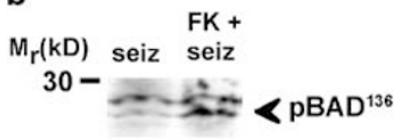

C

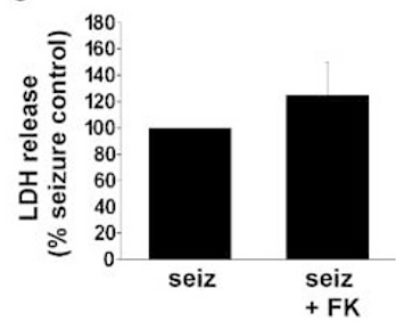

$\begin{array}{lll}\text { d } & F K+ \\ M_{r}(k D) & \text { seiz } & \text { seiz }\end{array}$

e

$M_{r}(k D)$ seiz seiz

$15--m<\mathrm{tBID}$

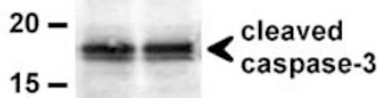

Figure 7 Inhibition of BAD does not prevent seizure-induced neuronal death (a) The calcineurin inhibitor FK506 (10 $\mu \mathrm{M}$ : $4 \mathrm{~h}$ ) reduced seizure-induced release of BAD from 14-3-3 and formation of the BAD-BCL-XI dimer. (b) Levels of phosphoBAD ${ }^{136}\left(\mathrm{pBAD}^{136}\right) 4 \mathrm{~h}$ after kyn withdrawal were higher in FK506treated than control seizure cultures. (c) Quantification of cell death revealed FK506 was not protective against seizure-induced neuronal injury. (d) Western blotting of FK506-treated cultures revealing persistence of BID cleavage despite BAD inhibition. (e) Western blotting of FK506-treated cultures revealing persistence of caspase-3 cleavage despite BAD inhibition. Immunoblots are representative of two independent experiments

The model employed in the present study is based on previously established systems for the study of injuryproducing seizure-like activity in vitro. ${ }^{28}$ This model bears significant differences to models of excitotoxicity in which glutamate agonists are exogenously applied to neuron cultures to model excitotoxicity. ${ }^{28}$ Our electrophysiological recordings confirmed that dramatic seizure-like spiking is induced on withdrawal of the chronic glutamate transmission block. Further, we found this elicits neuronal death as assessed by LDH and TUNEL assays. Interestingly, although CNQX was effective in inhibiting fast electrical activity, it was ineffective at inhibiting cell death following Kyn withdrawal. It appears that mediation of calcium entry, as opposed to spiking/action potentials per se, is required for cell death likely through NMDA receptors. Fura-2 calcium imaging experiments revealed that prominent calcium entry occurs on withdrawal of Kyn that is completely blocked by MK801 but not the AMPA receptor antagonist CNQX. These data therefore corroborate electrophysiological findings that it is calcium entry through NMDA receptors that is the principal stimulus for cell death in this model.

The mechanism by which seizures induce neuronal death is yet to be completely characterized, but morphological studies suggest that a mixture of necrotic and apoptotic mechanisms are likely to be involved. ${ }^{6,33,34}$ While ultrastructural examination of cells is requisite in definitive classification of cell death as apoptotic, necrotic or otherwise, high-power microscopic examination of TUNEL-positive cells in our studies confirmed that nuclear features consistent with apoptosis-like cell death were frequently present. Biochemical analysis has demon- 
strated upregulation of BCL-2 family proteins known to modulate apoptotic cell death in experimental and now human epileptic brain samples. , $9,35,36$ In our model of seizure-like activity in neuronal cultures, we detected a number of biochemical markers of apoptosis-like cell death including cleavage of BID and caspase-3, events previously reported in vivo following seizures. 8,10 However, studies are yet to functionally demonstrate roles for any of the BCL-2 family proteins in this injury setting. The mechanism by which these molecules exert these effects is still being understood but likely involve dimerization-mediated inactivation of antiapoptotic BCL-2/BCL-XI or direct coagonist actions with BAX and/ or BAK. ${ }^{17,18}$ While a small number of studies have examined expression of BCL-2 family proteins in brain following seizures, ${ }^{5,35,37}$ these have not addressed the functional responses of this pathway. Indeed, many BCL-2 family proteins are constitutively expressed in brain, even in the adult, $^{38,39}$ and may not require new protein expression to exert effects. ${ }^{40}$ Examination of the protein-protein binding events of BCL-2 family proteins is therefore essential in assessing the role of these molecular cell death regulators in brain injury.

Our initial examination by western blotting confirmed the constitutive expression of the principal components in the BAD pathway, but revealed little change after seizure-like activity despite ongoing cell death. This finding also demonstrates that any protein-protein binding changes cannot be a consequence of altered underlying expression levels. Functional interaction assessment by coimmunoprecipitation analysis revealed activation of the BAD pathway after seizure-like activity in vitro. We found the constitutive interaction complex of BAD with 14-3-3 to be present in control neuronal cultures, but following seizure-like activity there is rapid dephosphorylation and release of BAD, which subsequently dimerized with BCL-XI. This has previously been shown to free $B A X$ from $B C L-X I$, which then translocates to mitochondria to cause cytochrome $c$ release and engage the caspase pathway. ${ }^{18,23}$ Our study therefore provides functional evidence for the activation of BAD following seizures in vitro, complementing findings on neuronal apoptosis following exposure to exogenous glutamate receptor agonists, ${ }^{22}$ but contrasting events following mild NMDA receptor stimulation in which BAD is phosphorylated and inactivated. ${ }^{41}$

A number of protein kinases have been shown to phosphorylate and inactivate BAD including Akt (protein kinase B) and components of the MAP kinase pathway. ${ }^{31,32}$ In our cultures we detected constitutive activation of Akt, $\mathrm{MEK}_{1 / 2}, E R K_{1 / 2}$ and p90 RSK. Tonic activation of these pathways was confirmed by putatively selective inhibitors, which knocked down phosphorylation of $\mathrm{ERK}_{1 / 2}$ and Akt in a selective manner. However, inhibition of $M E K / E R K_{1 / 2}$ with U0126 or inhibition of Akt by LY294002 did not significantly worsen cell death outcome during seizures. This suggests that the MAP kinase and Akt pathways do not contribute effective counteractive measures during cell death triggered by seizure-like activity. Alternatively, the persistence of other cell death pathways may overwhelm the protective effects of these protein kinases. These findings also contrast previous work that suggested MAP kinase inhibition is neuroprotective after seizures in vitro. ${ }^{42}$ Additional studies are required to determine whether survival kinase pathways can intervene in the mechanism of cell death in this model.

There is a paucity of specific pharmacological agents with which to manipulate the BAD pathway. However, of those studied, the calcineurin inhibitor FK506 has been shown to block BAD dephosphorylation by calcineurin, ${ }^{22}$ although other cellular effects that might also yield neuroprotection have been attributed to FK506. ${ }^{43}$ We confirmed that FK506 markedly reduced activation of $B A D$ as assessed by reduced dimerization with BCL-XI, an increase in BAD 14-3-3 interaction and reduced seizure-induced dephosphorylation of BAD, but we did not in fact detect a significant protective effect with FK506. This was surprising since FK506 has previously been shown to protect against NMDA excitotoxicity, ${ }^{44}$ which may support the contention that this model of seizure-like activity in vitro bears significant differences to models of excitotoxicity that employ exogenously applied glutamate agonists. The lack of a protective effect of FK506 might be a consequence of residual $B A D$ binding to $B C L-X I$ being sufficient to trigger cell death. An alternative explanation is that other BCL-2 family proteins compensated for the reduced BAD effects, an event reported to occur for BCL-2 and caspase pathways. ${ }^{40,45}$ Indeed, we found that both BID truncation and caspase-3 activation persisted in neuronal cultures despite the suppression of the BAD pathway. This suggests that BAD may not contribute any significant cell killing effects in this model, or at best $B A D$ is reinforcing, with other pathways adequate to complete the cell death process. Further, the contribution of necrosis to the mechanism of cell death in this setting may be significant if in vivo morphological findings extend to this in vitro model. ${ }^{6,33}$ It may be of interest to compare the effects of combining a block on proapoptotic BCL-2 family proteins with enhancement of the effects of antiapoptotic members of the BCL-2 family to mitigate cell death associated with seizurelike activity. Also, the robust BID cleavage observed suggests upstream caspase-8 and/or death receptor pathways might next be examined in this model, since evidence for such pathways has been provided in vivo following seizures. ${ }^{10,46,47}$

Questions remain as to whether the present in vitro studies will extrapolate to in vivo seizure models or a clinical setting. In support of this are the similarities in caspase-3 activation seen presently to that previously observed by our group following seizures in vivo ${ }^{8}$ and in human temporal lobe resections from patients with intractable epilepsy. ${ }^{9}$ Whether seizure-induced neurodegeneration in these latter settings might lend themselves more effectively to pharmacological intervention to mitigate cell death is unknown, but now provides a basis for future research efforts. In conclusion, we have demonstrated the activation of the BAD pathway by analysis of BCL-2 family protein dimerization interactions in neurons subject to seizurelike activity. This pathway is likely triggered by the calciumdependent enzyme calcineurin downstream of NMDA receptors based on pharmacological manipulation with FK506 and glutamate receptor antagonists. However, its functional significance is challenged by the lack of neuroprotection afforded to cultures when the BAD pathway is blocked, suggesting that other pathways may either compensate for BAD when inactivated or even predominate in the mechanism by which seizures induce neuronal death in vitro. 


\section{Materials and Methods}

\section{Neuronal cell culture}

Hippocampal neuronal cultures were prepared from 1- to 3-day-old Sprague-Dawley rat pups. Briefly rat pups were anesthetized using isoflurane, decapitated and hippocampi were dissected and dissociated with papain (Worthington Biochemicals) and plated out in Neurobasal-A/ B27 media (Gibco) supplemented with $10 \mathrm{mM} \mathrm{Kyn}$ and $5 \mathrm{mM} \mathrm{MgCl}_{2}$. After 5 days, $1 \mu \mathrm{M}$ cytosine $\beta$-D-arabinofuranoside (Sigma) and $5 \mathrm{ng} / \mathrm{ml} \mathrm{bFGF}$ (Gibco) were added to the media. Cells were used after 3-4 weeks in culture.

Seizure-like activity was induced by incubating the cells in NeurobasalA/ B27 media without Kyn or magnesium for indicated time points (0$48 \mathrm{~h})$. Some cells were pretreated with AP-5 $(10 \mu \mathrm{M}), \mathrm{CNQX}(20 \mu \mathrm{M}), \mathrm{MK}$ $801(10 \mu \mathrm{M}), \mathrm{LY} 294002(10 \mu \mathrm{M}), \mathrm{U} 0126(10 \mu \mathrm{M})$ or FK506 $(10 \mu \mathrm{M}$, a gift from Dr. T Andoh), $10 \mathrm{~min}$ prior to Kyn withdrawal, and for the period of time of Kyn withdrawal. Some cells were incubated with staurosporine $(1 \mu \mathrm{M})$ for $0-48 \mathrm{~h}^{29}$

\section{Electrophysiology}

For electrophysiology experiments, cells were plated out on polylysinecoated glass coverslips at a density of 400000 cell/coverslip. Patch-clamp recordings were performed as described previously. ${ }^{30}$ Patch electrodes were constructed from thin-walled borosilicate glass $(1.5 \mathrm{~mm}$ diameter, WPI, Sarasota, FL, USA) on a two-stage puller (PP83, Narishige, Tokyo, Japan). The tips of the electrodes were normally heat polished on a Narishige microforge (Scientific Instruments Laboratory, Tokyo, Japan, Model MF-83) to a final diameter of 1-2 $\mu \mathrm{m}$. The patch electrodes had a resistance between 3 and $5 \mathrm{M} \Omega$ when filled with intracellular solution. Membrane potentials were recorded in current-clamp mode using Axopatch 1-D amplifiers (Axon Instruments, Foster City, CA, USA). Data were filtered at $2 \mathrm{kHz}$ and digitized on-line using Digidata 1320A DAC units (Axon Instruments). The on-line acquisition was done using pClamp software (versin 8.0, Axon Instruments).

Extracellular solution contained (in $\mathrm{mM}$ ): $140 \mathrm{NaCl}, 5.4 \mathrm{KCl}, 25 \mathrm{HEPES}$, 33 glucose, $1.3 \mathrm{CaCl}_{2}, 1.0 \mathrm{MgCl}_{2}, 10 \mathrm{KA}, \mathrm{pH} 7.4$ using $\mathrm{NaOH} ; 320$ 335 mOsm. Patch electrodes contained (in $\mathrm{mM}$ ): $140 \mathrm{KF}, 2.0 \mathrm{MgCl}_{2}, 1.0$ $\mathrm{CaCl}_{2}, 10$ HEPES, 11 EGTA, $4 \mathrm{MgATP}, \mathrm{pH} 7.3$, using $\mathrm{NaOH}$ (the final $\mathrm{Na}^{+}$ concentration is about $10 \mathrm{mM}$ ); $300 \mathrm{mOsm}$.

All electrophysiological experiments were performed at room temperature $\left(22-24^{\circ} \mathrm{C}\right)$. A multibarrel perfusion system (SF-77B, Warner Instrument $\mathrm{Co}$.) was employed to achieve a rapid exchange of solutions.

\section{Calcium imaging}

Calcium imaging was performed as previously described. ${ }^{30}$ Neurons grown on $25 \times 25 \mathrm{~mm}^{2}$ glass coverslips were washed three times with extracellular solution containing $10 \mathrm{mM} \mathrm{KA}$ and incubated with $5 \mu \mathrm{M}$ fura2-acetoxymethyl ester for $40 \mathrm{~min}$ at room temperature followed by wash three times and incubated in extracellular solution for $30 \mathrm{~min}$. Coverslips with fura-2-loaded cells were then transferred to a perfusion chamber on an inverted microscope (Nikon TE300). Cells were illuminated using a xenon lamp $(75 \mathrm{~W})$ and observed with a $\times 40$ UV fluor oil-immersion objective lens. Video images were obtained using a cooled CCD camera (Sensys KAF 1401, Photometrics). Digitized images were acquired, stored and analyzed in a PC-type computer controlled by Axon Imaging Workbench software (AIW2.1, Axon Instruments). The shutter and filter wheel (lambda 10-2) were also controlled by AIW to allow timed illumination of cells at either 340 or $380 \mathrm{~nm}$ excitation wavelengths. Fura-2 fluorescence was detected at an emission wavelength of $510 \mathrm{~nm}$. In all, $340 / 380$ ratio images were analyzed by averaging pixel ratio values in circumscribed regions of cells in the field of view. The values were exported from AIW to SigmaPlot 2000 for further analysis and plotting.

\section{Cell death assay}

For cell death assays, cells were grown in 24-well plates at a density of approximately 200000 cells/well. Following withdrawal of Kyn, lactate dehydrogenase $(\mathrm{LDH})$ release from hippocampal cells was determined using a cytotoxicity detection kit (Roche). Briefly, $100 \mu$ l of media were reacted with $100 \mu$ reagent, incubated at room temperature for $30 \mathrm{~min}$ and read on a spectrophotometer at 405 and $692 \mathrm{~nm}$.

\section{Western blotting}

For Western blotting, cells were plated out onto $10 \mathrm{~cm}$ polylysine-coated culture dishes (Primara; Becton Dickinson). Cell samples were collected at various time points following Kyn withdrawal and lysed in a nondenaturing buffer containing the protease inhibitors phenylmethylsulfonylfluoride (PMSF) $100 \mu \mathrm{g} / \mathrm{ml}$, aprotinin $1 \mu \mathrm{g} / \mathrm{ml}$, leupeptin $1 \mu \mathrm{g} / \mathrm{ml}$, pepstatin $1 \mu \mathrm{g} / \mathrm{ml}$, $\mathrm{NaF} 50 \mathrm{mM}, \mathrm{Na}_{3} \mathrm{VO}_{4} 2 \mathrm{mM}$ ). Protein concentration was determined by the Bradford reagent spectophotometrically at $A^{595}$. Protein samples (30$50 \mu \mathrm{g}$ ) were denatured in a gel-loading buffer at $100^{\circ} \mathrm{C}$ for $5 \mathrm{~min}$ and then loaded on $12 \%$ SDS-polyacrylamide gels. Proteins were transferred to polyvinylidene difluoride membranes and incubated with primary antibodies at $4^{\circ} \mathrm{C}$ overnight; anti-Akt, anti-phosphoAkt ${ }^{308,473}$, anti-BAD and anti-BAD ${ }^{136}$ (polyclonal; Cell Signaling Technology), anti-14-3-3 $\beta$ (monoclonal, Santa Cruz Biotechnology, Santa Cruz, CA, USA) and antiBCL-XI (monoclonal; BD Transduction Laboratories, Lexington, KY, USA). Membranes were incubated with either anti-rabbit IgG or anti-mouse IgG conjugated to HRP (Cell Signalling Technology, Beverly, MA, USA) followed by chemiluminescensce detection (NEN Life Science Products, Boston, MA, USA) and then exposed to Kodak film (Biomax). Images were captured using a Dage 72 camera and gel bands analyzed using gel scanning-integrated optical density software (Bioquant, Nashville, TN, USA).

\section{Immunoprecipitation}

Cells were plated out on $10 \mathrm{~cm}$ dishes at five million cell/dish. Total protein $(0.5 \mathrm{mg})$ was incubated with $2-4 \mu \mathrm{g}$ primary antibody and incubated at $4^{\circ} \mathrm{C}$ overnight. Agarose-A/G beads (Santa Cruz) $(100 \mu \mathrm{g})$ were added and samples incubated for a further $2 \mathrm{~h}$ at $4^{\circ} \mathrm{C}$. Samples were washed using an immunoprecipitation kit (IP50, Sigma). The protein/bead mixture was denatured at $95^{\circ} \mathrm{C}$ for $10 \mathrm{~min}$ and then loaded onto $12 \%$ SDSpolyacrylamide gels. Blots were subjected to Western blotting as above.

\section{DNA fragmentation analysis}

DNA fragmentation was assessed using a fluorescein TUNEL kit according to the manufacturer's instructions (Roche). Briefly, coverslips were incubated with a reaction mixture containing terminal deoxynucleotidyl transferase and fluorescein-conjugated nucleotides for $1 \mathrm{~h}$ at $37^{\circ} \mathrm{C}$. Coverslips were washed and mounted as described above. 


\section{Data analysis}

Data are presented as mean \pm standard error of the mean (S.E.M.) of $n$ determinations. Data are analyzed using one-way or two-way analysis of variance (ANOVA) with appropriate post hoc tests (Graphpad Prism). Significance was accepted at $P<0.05$.

\section{Acknowledgements}

We thank Ron Geison for technical support. This work was supported by National Institutes of Health Grants NS39016 (to RPS and DCH) and NS41935 (to DCH).

\section{References}

1. Kalviainen R, Salmenpera $T$, Partanen $K$, Vainio $P$, Riekkinen $P$, Pitkanen $A$ (1998) Recurrent seizures may cause hippocampal damage in temporal lobe epilepsy. Neurology 50: 1377-1382

2. O'Brien TJ, So EL, Meyer FB, Parisi JE, Jack CR (1999) Progressive hippocampal atrophy in chronic intractable temporal lobe epilepsy. Ann. Neurol. 45: 526-529

3. Briellmann RS, Berkovic SF, Syngeniotis A, King MA, Jackson GD (2002) Seizure-associated hippocampal volume loss:A longitudinal magnetic resonance study of temporal lobe epilepsy. Ann. Neurol. 51: 641-644

4. Pollard H, Charriaut-Marlangue $\mathrm{C}$, Cantagrel S, Represa A, Robain O, Moreau J, Ben-Ari Y (1994) Kainate-induced apoptotic cell death in hippocampal neurons. Neuroscience 63: 7-18

5. Gillardon F, Wickert H, Zimmermann M (1995) Up-regulation of bax and downregulation of bcl-2 is associated with kainate-induced apoptosis in mouse brain. Neurosci. Lett. 192: 85-88

6. Sloviter RS, Dean E, Sollas AL, Goodman JH (1996) Apoptosis and necrosis induced in different hippocampal neuron populations by repetitive perforant path stimulation in the rat. J. Comp. Neurol. 366: 516-533

7. Bengzon J, Kokaia Z, Elmer E, Nanobashvili A, Kokaia M, Lindvall O (1997) Apoptosis and proliferation of dentate gyrus neurons after single and intermittent limbic seizures. Proc. Natl. Acad. Sci. USA 94: 10432-10437

8. Henshall DC, Chen J, Simon RP (2000) Involvement of caspase-3-like protease in the mechanism of cell death following focally evoked limbic seizures. J. Neurochem. 74: 1215-1223

9. Henshall DC, Clark RS, Adelson PD, Chen M, Watkins SC, Simon RP (2000) Alterations in bcl-2 and caspase gene family protein expression in human temporal lobe epilepsy. Neurology 55: 250-257

10. Henshall DC, Bonislawski DP, Skradski SL, Meller R, Lan J-Q, Simon RP (2001) Cleavage of Bid may amplify caspase-8-induced neuronal death following focally evoked limbic seizures. Neurobiol. Dis. 8: 568-580

11. Green DR, Reed JC (1998) Mitochondria and apoptosis. Science 281: 13091312

12. Kroemer G, Reed JC (2000) Mitochondrial control of cell death. Nat. Med. 6: 513-519

13. Korsmeyer SJ, Wei MC, Saito M, Weiler S, Oh KJ, Schlesinger PH (2000) Proapoptotic cascade activates BID, which oligomerizes BAK or BAX into pores that result in the release of cytochrome $c$. Cell Death Differ. 7: 1166-1173

14. Wei MC, Zong WX, Cheng EH, Lindsten T, Panoutsakopoulou V, Ross AJ, Roth KA, MacGregor GR, Thompson CB, Korsmeyer SJ (2001) Proapoptotic $B A X$ and BAK: a requisite gateway to mitochondrial dysfunction and death. Science 292: 727-730

15. Wang K, Yin XM, Chao DT, Milliman CL, Korsmeyer SJ (1996) BID: a novel BH3 domain-only death agonist. Genes Dev. 10: 2859-2869

16. Desagher S, Osen-Sand A, Nichols A, Eskes R, Montessuit S, Lauper S, Maundrell K, Antonsson B, Martinou JC (1999) Bid-induced conformational change of Bax is responsible for mitochondrial cytochrome $c$ release during apoptosis. J. Cell Biol. 144: 891-901

17. Eskes R, Desagher S, Antonsson B, Martinou JC (2000) Bid induces the oligomerization and insertion of Bax into the outer mitochondrial membrane. Mol. Cell Biol. 20: 929-935
18. Yang E, Zha J, Jockel J, Boise LH, Thompson CB, Korsmeyer SJ (1995) Bad, a heterodimeric partner for $\mathrm{Bcl}-\mathrm{XL}$ and $\mathrm{Bcl}-2$, displaces $\mathrm{Bax}$ and promotes cell death. Cell 80: 285-291

19. Zha J, Harada H, Yang E, Jockel J, Korsmeyer SJ (1996) Serine phosphorylation of death agonist $B A D$ in response to survival factor results in binding to $14-3-3$ not BCL-X(L). Cell 87: 619-628

20. Subramanian RR, Masters SC, Zhang H, Fu H (2001) Functional conservation of 14-3-3 isoforms in inhibiting bad-induced apoptosis. Exp. Cell Res. 271: $142-151$

21. Masters SC, Yang H, Datta SR, Greenberg ME, Fu H (2001) 14-3-3 inhibits Bad-induced cell death through interaction with serine-136. Mol. Pharmacol. 60: 1325-1331

22. Wang HG, Pathan N, Ethell IM, Krajewski S, Yamaguchi Y, Shibasaki F, McKeon F, Bobo T, Franke TF, Reed JC (1999) Ca2+-induced apoptosis through calcineurin dephosphorylation of BAD. Science 284: 339-343

23. Kelekar A, Chang BS, Harlan JE, Fesik SW, Thompson CB (1997) Bad is a $\mathrm{BH} 3$ domain-containing protein that forms an inactivating dimer with $\mathrm{Bcl}-\mathrm{XL}$. Mol. Cell Biol. 17: 7040-7046

24. Springer JE, Azbill RD, Nottingham SA, Kennedy SE (2000) Calcineurinmediated BAD dephosphorylation activates the caspase-3 apoptotic cascade in traumatic spinal cord injury. J. Neurosci. 20: 7246-7251

25. Zhu Y, Yang GY, Ahlemeyer B, Pang L, Che XM, Culmsee C, Klumpp S, Krieglstein $\mathrm{J}$ (2002) Transforming growth factor-beta 1 increases bad phosphorylation and protects neurons against damage. J. Neurosci. 22: 3898-3909

26. Jin K, Mao XO, Zhu Y, Greenberg DA (2002) MEK and ERK protect hypoxic cortical neurons via phosphorylation of Bad. J. Neurochem. 80: 119-125

27. Furshpan EJ (1989) A cell-culture approach to the study of seizure activity. Q. J. Exp. Physiol. 74: 975-985

28. Furshpan EJ, Potter DD (1989) Seizure-like activity and cellular damage in rat hippocampal neurons in cell culture. Neuron 3: 199-207

29. Meller R, Skradski SL, Simon RP, Henshall DC (2002) Expression, proteolysis and activation of caspases 6 and 7 during rat $\mathrm{C} 6$ glioma cell apoptosis. Neurosci. Lett. 324: 33-36

30. Xiong Z, Lu W, MacDonald JF (1997) Extracellular calcium sensed by a novel cation channel in hippocampal neurons. Proc. Natl. Acad. Sci. USA 94: 70127017

31. Datta SR, Dudek H, Tao X, Masters S, Fu H, Gotoh Y, Greenberg ME (1997) Akt phosphorylation of BAD couples survival signals to the cell-intrinsic death machinery. Cell 91: 231-241

32. Hayakawa J, Ohmichi M, Kurachi H, Kanda Y, Hisamoto K, Nishio Y, Adachi K, Tasaka K, Kanzaki T, Murata Y (2000) Inhibition of BAD phosphorylation either at serine 112 via extracellular signal-regulated protein kinase cascade or at serine 136 via Akt cascade sensitizes human ovarian cancer cells to cisplatin. Cancer Res. 60: 5988-5994

33. Fujikawa DG, Shinmei SS, Cai B (2000) Kainic acid-induced seizures produce necrotic, not apoptotic, neurons with internucleosomal DNA cleavage: implications for programmed cell death mechanisms. Neuroscience 98: 41-53

34. Fujikawa DG, Shinmei SS, Cai B (2000) Seizure-induced neuronal necrosis: implications for programmed cell death mechanisms. Epilepsia 41: S9-S13

35. Lopez E, Pozas E, Rivera R, Ferrer I (1999) Bcl-2, Bax and Bcl-x expression following kainic acid administration at convulsant doses in the rat. Neuroscience 91: 1461-1470

36. Henshall DC, Skradski SL, Lan J, Ren T, Simon RP (2001) Increased Bcl-w expression following focally evoked limbic seizures in the rat. Neurosci. Lett. 305: 153-156

37. Kondratyev A, Sahibzada N, Gale K (2001) Electroconvulsive shock exposure prevents neuronal apoptosis after kainic acid-evoked status epilepticus. Brain Res. Mol. Brain Res. 91: 1-13

38. Sadoul R (1998) Bcl-2 family members in the development and degenerative pathologies of the nervous system. Cell Death Differ. 5: 805-815

39. Krajewska M, Mai JK, Zapata JM, Ashwell KW, Schendel SL, Reed JC, Krajewski S (2002) Dynamics of expression of apoptosis-regulatory proteins $\mathrm{Bid}, \mathrm{Bcl}-2, \mathrm{Bcl}-\mathrm{X}$, Bax and Bak during development of murine nervous system. Cell Death Differ. 9: 145-157

40. Putcha GV, Harris CA, Moulder KL, Easton RM, Thompson CB, Johnson Jr EM (2002) Intrinsic and extrinsic pathway signaling during neuronal apoptosis: lessons from the analysis of mutant mice. J. Cell Biol. 157: 441-453 
41. Yano S, Tokumitsu H, Soderling TR (1998) Calcium promotes cell survival through CaM-K kinase activation of the protein-kinase-B pathway. Nature 396: 584-587

42. Murray B, Alessandrini A, Yee AG, Cole AJ, Furshpan EJ (1998) Inhibition of the p44/42 MAP kinase pathway protects hippocampal neurons in a cell-culture model of seizure activity. Proc. Natl. Acad. Sci. USA 95: 11975-11980

43. Snyder SH, Lai MM, Burnett PE (1998) Immunophilins in the nervous system. Neuron 21: 283-294

44. Dawson TM, Steiner JP, Dawson VL, Dinerman JL, Uhl GR, Snyder SH (1993) Immunosuppressant FK506 enhances phosphorylation of nitric oxide synthase and protects against glutamate neurotoxicity. Proc. Natl. Acad. Sci. USA 90: 9808-9812

45. Zheng TS, Hunot S, Kuida K, Momoi T, Srinivasan A, Nicholson DW, Lazebnik $Y$, Flavell RA (2000) Deficiency in caspase-9 or caspase-3 induces compensatory caspase activation. Nat. Med. 6: 1241-1247

46. de Bock F, Dornand J, Rondouin G (1996) Release of TNF alpha in the rat hippocampus following epileptic seizures and excitotoxic neuronal damage. Neuroreport 7: 1125-1129

47. Tan Z, Levid J, Schreiber SS (2001) Increased expression of Fas (CD95/APO-1) in adult rat brain after kainate-induced seizures. Neuroreport 12: $1979-1982$ 